\title{
Present States and Design Concept about Flexible DC Distribution System
}

\author{
Xiaodong Yuan ${ }^{1,}$, Dan Liü ${ }^{1, b}$ and Qiang $\mathrm{Li}^{1, \mathrm{c}}$ \\ 1State Grid Jiangsu Electric Power Company, Nanjing 211103, China; \\ a387624995@qq.com, b158269975@qq.com,c914444125@qq.com
}

\begin{abstract}
Keywords: Direct current, renewable energy, distributed resources, electric power transformer, multi-level DC distribution system.
\end{abstract}

\begin{abstract}
DC power distribution system can integrate the distributed power generation system effectively and fully utilize this important event to maximum. It can increase operation efficiency, enhance service reliability, improve power quality and interconnect distributed generations safely, this is a new developing opportunities for distributing technology. The basic principle and key implementation technology of DC power distribution system are summarized. The present states of research and the feasibility of DC distribution technique are described. An electronic power transformer-based multi-level DC distribution system model is introduced. As a case study, a concrete low voltage DC distribution system for residential application is designed in more detail and is indicated by simulation. Finally, the prospect of the DC distribution system is given combining with the existing power electronics technology.
\end{abstract}

\section{Introduction}

Nowadays with the development of social economy, the demand of electric power is growing, so the traditional distribution systems are facing more and more challenges.

1) In response to environmental degradation and energy depletion, all countries around the world attach great importance to distributed generation and energy storage technology, they have been developing rapidly. But it is a challenge to the existing technology to integrate all of these new DC power supply, variable frequency AC power supply and the traditional power frequency AC power grid into an interconnection.

2) Urban development and construction made the construction of power distribution system and power line limited. On the one hand, that led to the power supply radius is bigger and bigger, which puts forward high requirements to the power supply network's transmission ability; On the other hand, the reactive power support in load center is relatively insufficient, which is easy to cause the security issues such as AC system voltage collapse.

3) There are more and more DC loads and loads including DC link. So when AC power supply power to the load, the AC/DC transformer will reduce the efficiency. It is more easily to integrate renewable energy generators and energy storage devices with DC power distribution network than with AC power distribution network

4) Users are increasingly demanding on the power supply reliability, the failure rate of traditional overhead line is on the high side, the power supply radius of power cable is limited due to the limitation of charging current, this method becomes more and more difficult to meet the needs of users.

5) The wide use of power electronic equipment and influence of special loads such as electric arc stove and electrical railways make harmonic problem deteriorated increasingly, and harmonic becomes the primary factor influencing power quality.

6) Power grid intelligence has become an inevitable trend, smart grid puts forward high requirements to the controllability of power grid. The controllability of traditional AC distribution network is low. 
How to properly deal with the above issues is the current and future problem that distribution system needs to face for a long period of time. With the development of power electronics technology, the DC power distribution system will provide a new way to solve this problem.

For a long time, only some special occasions adopt DC power supply, such as the communication data center, rail transportation, industrial production line ${ }^{[1-4]}$. But in recent years, DC power distribution technology research already arose the domestic and foreign scholars' attention ${ }^{[5-7]}$.

The concept of low-voltage DC power distribution system is put forward from the perspective of power system, and 2 typical systems are given ${ }^{[8-9]}$. The idea of a future power system dominated by DC is put forward ${ }^{[10-11]}$, which thinks multi-level DC circular grid structure accords with the practice of the future of China's electricity grid. It is proposed that the DC power distribution network is constructed by using high temperature superconducting DC cable, which provides a new solution to the problem of DC high current breaking ${ }^{[12]}$.The fault types, protection principles and other issues in typical low-voltage DC power distribution network are analyzed ${ }^{[13-17]}$.The concept of DC micro grid is proposed from the perspective of distributed generation. The problem of voltage stability of DC power supply system in different fields is analyzed ${ }^{[18]}$.

In general, the current study of DC power distribution technology mainly concentrated in some special field and aimed at the end of low voltage power supply system, the direct study about DC power distribution technology from the perspective of power system is relatively less. In this paper, the characteristics of DC power distribution will be summarized and the key technologies will be analyzed to provide the reference for the further research in the future.

\section{The characteristics of DC power distribution technology}

DC power distribution technology refers to the power transmission technology that the DC power distribution system works as the dominant in the distribution network. Compared with AC power distribution system, DC power distribution technology has many potential advantages.

1) DC power distribution is more reliable.

The quantity of power lines in the DC power distribution network is 2, it is more reliable than the AC power distribution network under the same voltage level. When one of the two lines is broken, the other line can form a loop with the earth and transmits some or all of the power right along. Single-phase instantaneous grounding fault accounted for $80 \% \sim 90 \%$ of the total number of line failures. After grounding fault happens, the DC power distribution network can respond quickly and the recovery time is short, the system can restart or run down the voltage to handle with the failure and restore normal operation ${ }^{[19]}$.

For the low voltage DC power distribution, the high reliability of the power supply can be guaranteed by using the multi bus redundancy technique. In addition, the power electronic converter is adopted to make the DC power distribution system to form its own protection area, and the faults in each area will not affect the external system.

2) DC power distribution is more efficient.

In the DC transmission and distribution system, there is no network loss caused by the transmission of reactive power and the skin effect, the network loss is much lower than that of the AC transmission and distribution lines. The loss of DC power distribution system is mainly concentrated in the part of power electronic converter, but the efficiency of the latest DC converter has been up to $99 \%{ }^{[20]}$. With the gradual maturity of the power electronic devices, the efficiency of the converter is expected to be further enhanced.

On the other hand, there are more and more DC loads and loads including DC link, such as electronic products, DC motors and EVs. The efficiency will be higher when DC power is provided for these loads.

3) There is no problems about frequency stability, reactive power and AC charging current and other issues

Voltage amplitude, frequency and phase are controlled in the operation of the AC system, while only the voltage amplitude should be controlled in the operation of the DC system. There is no 
problem about frequency stability and reactive power. For urban distribution systems mainly consisting of cables, the equivalent capacitance of the power cable is relatively large, the capacitive current level in medium voltage cable distribution network is too high, accordingly the wasting of circuitry increases and the transmission capacity decreases. The above problems can be solved if the DC transmission is adopted.

In addition, the power distribution capacity of the DC power distribution network is large, the power supply radius is long, it can improve the power quality and it is easy to realize the interconnection of distributed power supply and so on.

\section{The challenge of DC power distribution technology}

The typical DC power distribution system is shown in figure 1, but there are so many challenges and key technology to research before the true realization of the DC distribution mode.

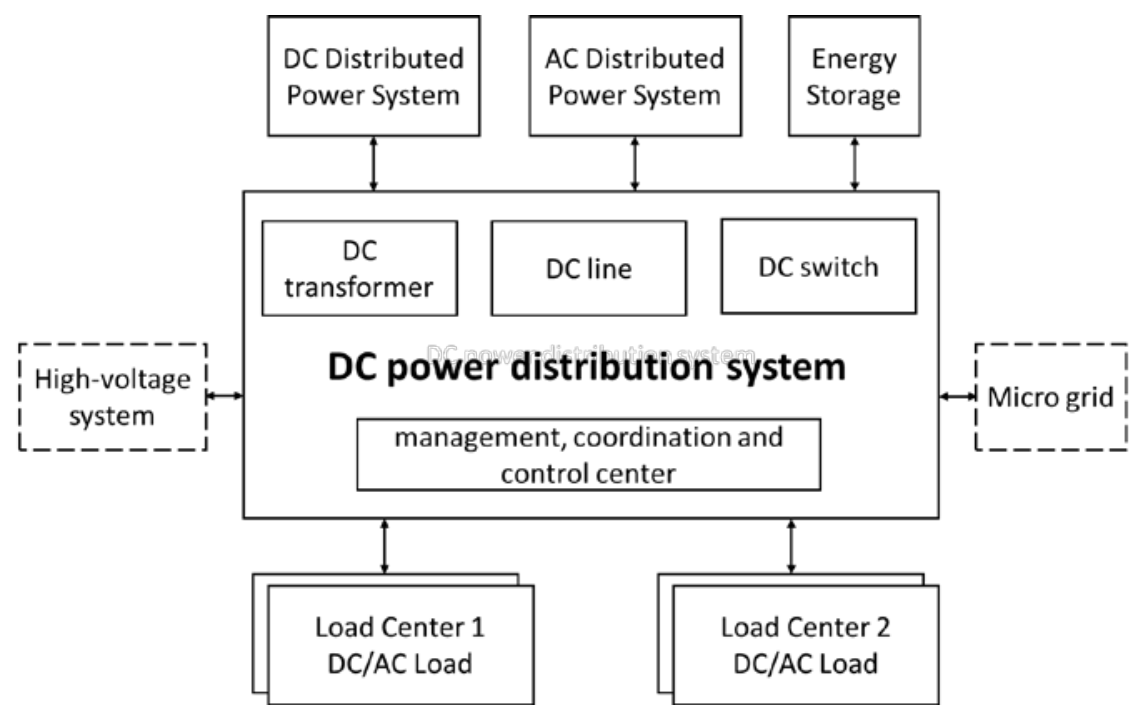

Fig. 1 Basic structure of DC distribution system

Although the development of DC power distribution has made great progress and development, but there are still a lot of problems, such as interruption of DC current, standardization of DC power supply, the control strategy and reliability of DC power supply and DC/DC converter with large capacity and so on.

1) Interruption of high-voltage DC transmission

Circuit breakers can interrupt various levels of current during the zero-crossing of the AC current in the AC system. But DC can't do this without zero crossing, the HVDC have to cross zero when interrupting, it is a higher requirement for the circuit Breaker as an HVDC Switching Element and its control system.

2) Standardization of DC power supply

The determination of voltage level standards and grid voltage is important for the development of DC power supply. DC distribution system will contain a number of voltage level distribution network. The parameter of voltage level has a fundamental influence on the whole system. The selection of voltage level should focus on 3 factors: Power supply distance of DC power distribution network (radius); electrical insulation and protection; system cost and design difficulty.

3) The control strategy and reliability of DC power supply

The output power characteristics of all kinds of new energy and distributed power are not the same. It has the characteristics of intermittent, complexity, diversity and instability. When the new energy and distributed power source are connected to DC power supply, the structure of the system will be changed and power flow will be more uncertain. So power grid protection, power flow control and harmonic effect should be taken into account. More and more study should get on in theory, implement methods and technique to evaluate the reliability of distribution system. Few scholars have conducted a comprehensive evaluation of the reliability of DC power system. 
4) $\mathrm{DC} / \mathrm{DC}$ converter with large capacity

The technology of DC/DC converter following $1 \mathrm{~kW}$ is more mature and have been widely used in the module power supply and other fields. At home and abroad, the research and development of large power DC/DC converter for DC power system is still in the prototype stage, there is no mature product. The emphases and difficulties of the process are control and protection strategies for each part of the circuit, development of transformer with large capacity and high frequency, serial and parallel technology of high power self-commutated power electronic devices.

Therefore, the large scale application of DC power supply system also has technical and economic problems at present.

\section{Case of DC power distribution system}

There is a conception of the DC power distribution network based on electronic power transformers in figure 2. It is composed of multi-level DC network to meet the requirements of power transmission and distribution in different range, and allows users to access small distributed power and large new energy power generation.

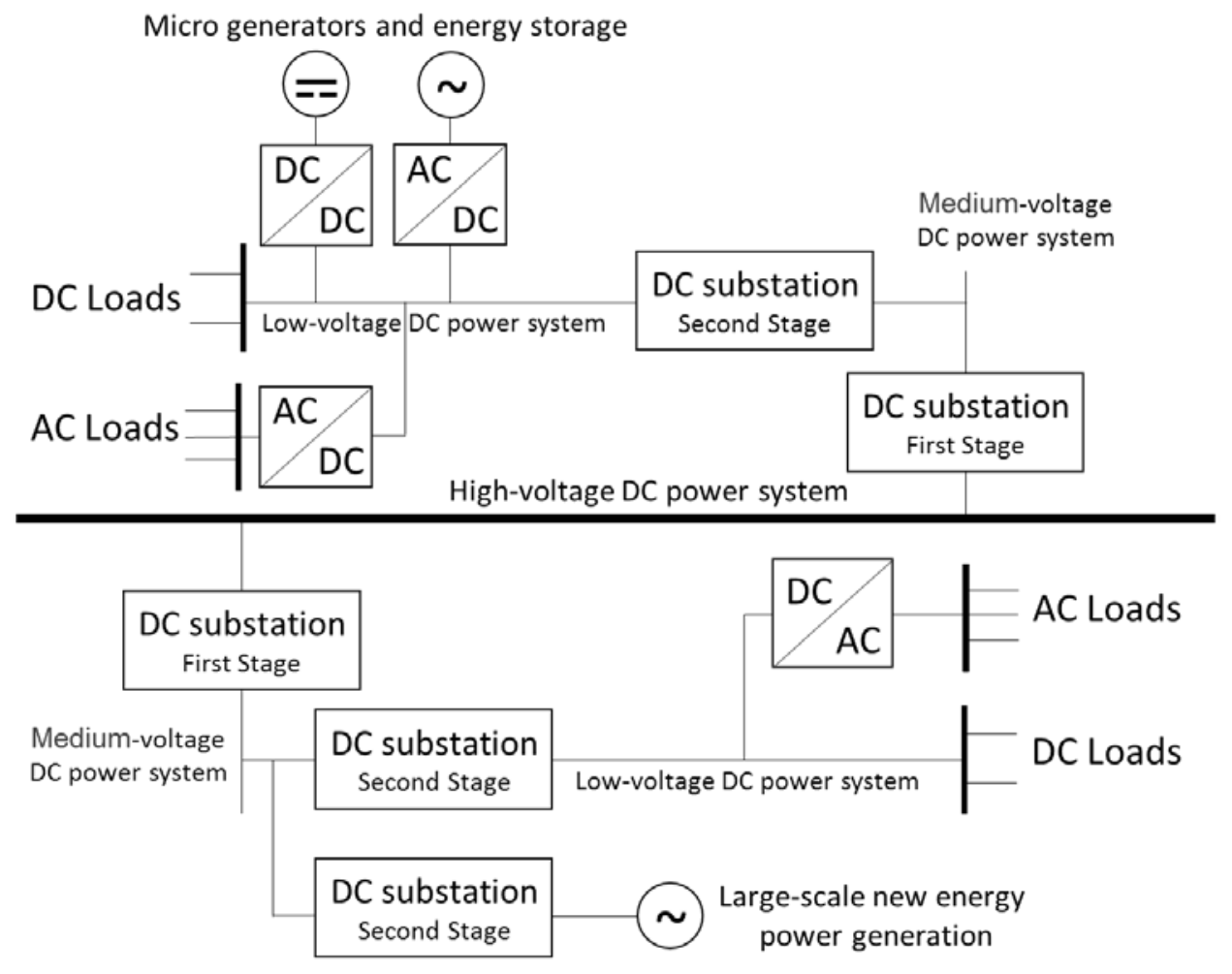

Fig. 2 Multi-level DC distribution network

This system's merits are mainly as follows: 1) Decoupling between different levels of DC power grid; 2) The fast regulating ability of the electronic power transformer can effectively limit the fault current rise, what can reduce the requirements of DC switching equipment.

However, the full DC power distribution network is still only a vision. In the near future, the most likely to take the lead in realizing the DC power system is the low voltage power distribution system at the end of the distribution network. Such as household power supply system and building power supply system.

There is a design case of terminal DC power distribution system taking the household power supply system as an example in figure 3 . It takes the following into consideration: 1 ) The photovoltaic power generation capacity is $3 \mathrm{~kW} ; 2$ ) In order to improve the reliability of power supply, the system is equipped with energy storage unit (storage battery). 3) Meeting the AC load (maximum 3kW) and DC load (maximum 1.5kW) power demand; 4) Keeping the existing communication system (220V). 


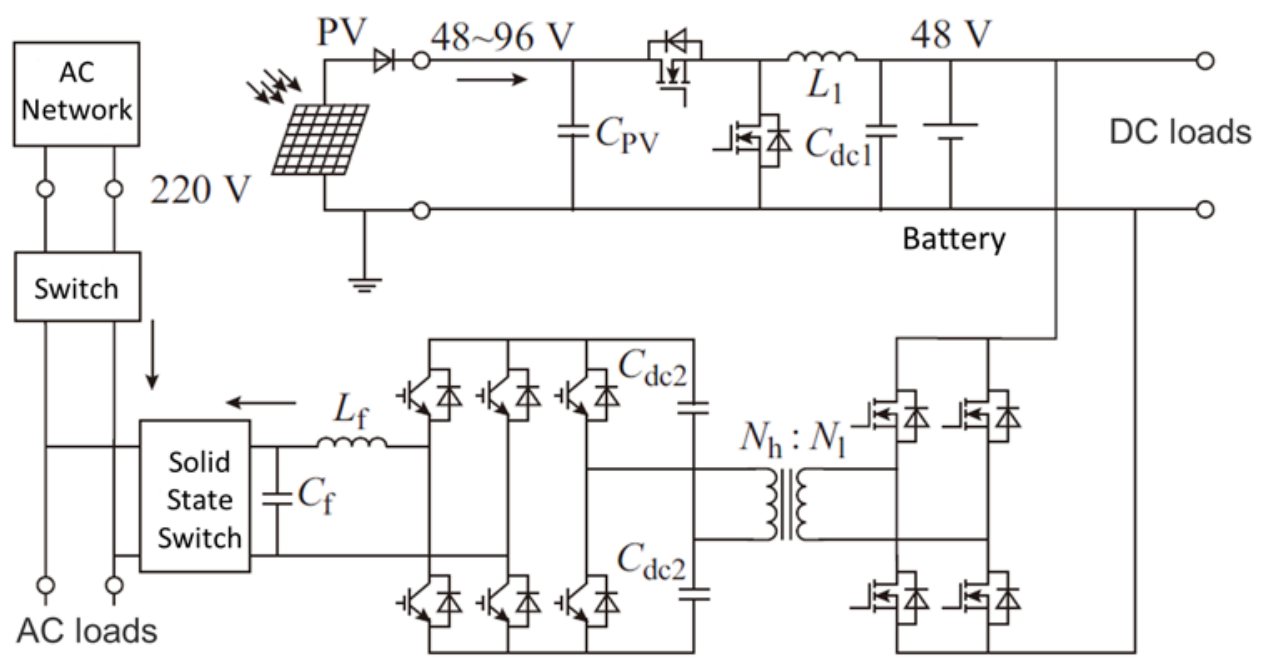

Fig. 3 Basic structure of residential DC distribution system

The characteristic of the system structure included five aspects. 1. Voltage level of DC bus is $48 \mathrm{~V}$, it is a relatively safety voltage. 2 . The battery energy storage unit is directly connected to the DC bus. This method is of high reliability and efficiency. 3. The PV grid-connected system was accessed to the DC power system through the simplest Buck converter. 4. The $48 \mathrm{~V}$ DC bus is a negative grounded DC two-wire system and isolated from 220V AC bus in voltage. 5. It allows bi-directional power flow between the DC bus and the AC bus, then Photovoltaic power energy can be fully utilized and the power supply reliability of AC and DC load is considered.

The simulation is carried out under the following conditions based on this system. The system is running off-grid at first, PV is the only source of power. DC load of $1.5 \mathrm{~kW}$, the remaining energy is provided by the battery. After $0.1 \mathrm{~s}, 3 \mathrm{~kW}$ AC load is accessed. After $0.5 \mathrm{~s}$, the system is connected with the grid. At 1s, the maximum output power of photovoltaic power begins to decrease. The simulation results of the whole process are shown in figure 4.

According to the above simulation result, before $0.1 \mathrm{~s}$ the power generation of photovoltaic power is greater than the load required, the excess energy is used to charge the battery. After the AC load is accessed, the PV power output power is lacking, the shortfall is supplied by battery storage. After the system is connected into the AC power grid, energy shortage is supplied by power grid. If the power of the photovoltaic power is too small to support the DC load, the power grid will supply energy to the DC load through the inverter.

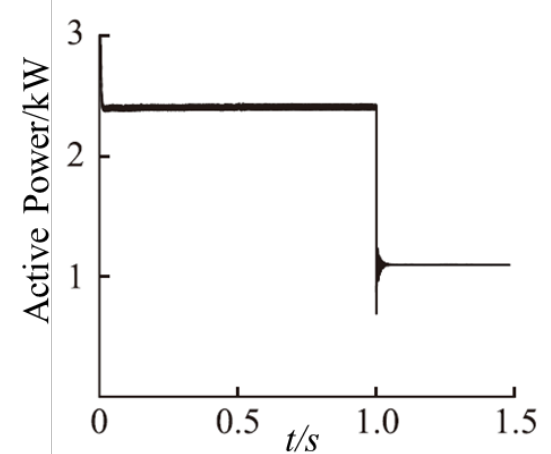

(a)Power supplied by the PV generation

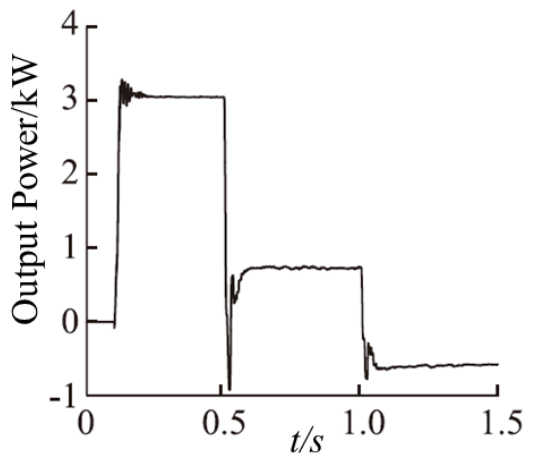

(b) Inverter output power

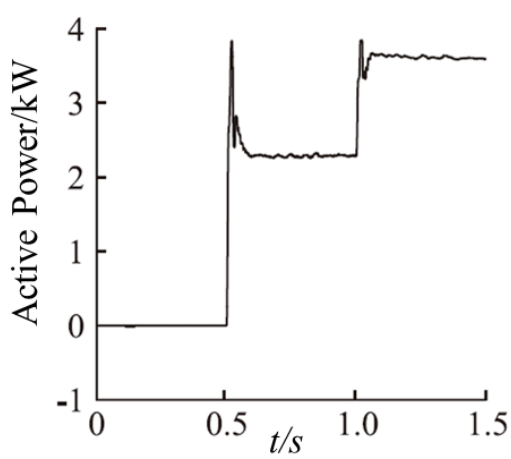

(c)Power supplied by the power grid

Fig. 4 Simulation results of residential DC distribution system

It can be seen from the above micro terminal distribution system that the power flow can be easily implemented in the DC network. 


\section{Conclusion}

DC power distribution system has the potential to solve the challenges of modern distribution system. Intensifying the research on the basic problems such as the network structure and the selection of voltage level of the DC power distribution system is the most important task now. Research on low cost, high efficiency power conversion and control technology, the development of large capacity DC switching equipment and the development of high reliability protection system are the keys to promote the development of DC power distribution technology. Although the operation control of DC power distribution system is much simpler than that of AC system, the operation and control of DC power distribution system has its special characteristics, especially DC distribution system has a lot of power electronic converters. The power electronic converter can improve the controllability of DC system, and it also increases the complexity of the system. This paper is a preliminary exploration of the DC power distribution system, further research needs to be carried out.

\section{References}

[1] R. Verma, S. Gupta. A ZVZCS three-phase boost dc-dc converter distributing 400VDC in Telco and data centers to improve energy efficiency[C]//Computational Intelligence and Information Technology, 2013. CIIT 2013. Third International Conference on. IET, 2013: 598-604.

[2] P. Sreeja, L.P. Suresh. Optimized design of ZVZCS switched non isolated DC-DC boost converter with high voltage gain[C]// Circuits, Power and Computing Technologies (ICCPCT), 2013 International Conference on. IEEE, 2013:500 - 505.

[3] J.G. Ciezki, R.W. Ashton. Selection and stability issues associated with a navy shipboard DC zonal electric distribution system[J]. Power Delivery, IEEE Transactions on, 2000, 15(2): 665-669.

[4] D. Paul. DC traction power system grounding[J]. Industry Applications, IEEE Transactions on, 2002, 38(3): 818-824.

[5] P. Salonen, T. Kaipia, P. Nuutinen, et al. An LVDC Distribution System Concept[J]. Helsinki University of Technology, 2008.

[6] P. Nuutinen, P. Salonen, P. Peltoniemi, et al. Customer-End Inverter in an LVDC Distribution Network[J]. Australian Journal of Physiotherapy, 2008, 47(1):7-16.

[7] L.G. Lin, M.U. Yu qiang, Y.L. Gao, et al. Low-Voltage Direct Current Distribution System Analysis and Existing Technical Issue[J]. Electrotechnics Electric, 2010.

[8] D. Salomonsson, A. Sannino. Low-voltage DC distribution system for commercial power systems with sensitive electronic loads[J]. Power Delivery, IEEE Transactions on, 2007, 22(3): 1620-1627.

[9] T. Kaipia, P. Salonen, J. Lassila, et al. Application of low voltage DC-distribution system-a techno-economical study[C]//19th Int. Conf. on Electricity Distribution. 2007.

[10] S.W. Eckroad. Superconducting DC cables for high power transport over long distances[C]//IASS Workshop Transporting Tens of GWatts of Green Power to the Market. 2011.

[11] L.Y. Xiao, L.Z. Lin. Construction of unified new-energy based power grid and promotion of China's smart grid[J]. Advanced Technology of Electrical Engineering \& Energy, 2009.

[12] Y. Miura, R. Sato, M. Saisho, et al. DC loop type superconducting distribution system including various distributed generations[J]. Applied Superconductivity, IEEE Transactions on, 2007, 17(2): 2335-2338. 